\title{
Proliferative Potentials of Intracranial Chordomas with a Reference to Extracranial Chordomas
}

\author{
Akira Matsuno $^{1}$, Tomio Sasaki², Tadashi Nagashima ${ }^{1}$, Takaaki Kirino ${ }^{3}$ and \\ R. Yoshiyuki Osamura ${ }^{4}$ \\ ${ }^{1}$ Department of Neurosurgery, Teikyo University Ichihara Hospital, 3426-3 Anegasaki, Ichihara City, Chiba 299-0111, \\ ${ }^{2}$ Department of Neurosurgery, Gumma University School of Medicine, 3-39-22 Showa-machi, Maebashi, Gumma 371-8511, \\ ${ }^{3}$ Department of Neurosurgery, University of Tokyo Hospital, 7-3-1 Hongo, Bunkyo-ku, Tokyo 113-8655 and ${ }^{4}$ Department \\ of Pathology, Tokai University School of Medicine, Boseidai, Isehara City, Kanagawa 259-1100
}

Received March 5, 2001; accepted July 6, 2001

\begin{abstract}
Some intracranial chordomas are known to have frequent recurrence in their clinical course. The biological features regulating recurrence of intracranial chordomas has not been elucidated. We studied the proliferative potentials of chordomas with an immunohistochemical staining method using anti-Ki-67 antibody, MIB-1, together with an immunohistochemical examination on the expression of $\mathrm{p} 53$ protein. The correlation among MIB-1 staining indices, the immunoreactivities of p53 protein and clinical courses of intracranial chordomas was analyzed retrospectively, and the statistically significant correlation between MIB-1 stain-
\end{abstract}

ing index ( $\mathrm{SI}$ ) and recurrence has been clarified. The mean MIB-1 SI of recurrent tumors was $10.2 \%$, which was higher than that of non-recurrent tumors $(2.8 \%)$. The p53 immunopositivity correlated well with recurrence and high MIB-1 SI. Literature review also showed the importance of MIB-1 SI and p53 overexpression in extracranial chordomas. In conclusion, both the examination on proliferative potentials of chordomas using MIB-1 SI and the study on the immunoreactivity of p53 protein, are important for their biological and histopathological analyses and the prediction of future recurrence.

Key words: Intracranial chordoma, Proliferative potential, MIB-1, p53 protein, Recurrence

\section{Introduction}

Chordomas are usually slowly growing tumors arising from the remnants of notochordal tissues $[2,17]$. They are most often located on the sacrococcygeal region, followed by spheno-occipital region, vertebral region, and other regions $[7,11,16,18,31,35]$. Some of them have frequent recurrence and distant metastasis in the late stage of the disease [5, 10, 11, 13, 33, 35], and finally cause death. Recurrence of chordomas is considered to be affected by various clinical, biological and histopathological factors.

Correspondence to: Akira Matsuno, M.D., Ph.D., Department of Neurosurgery, Teikyo University Ichihara Hospital, 3426-3 Anegasaki, Ichihara City, Chiba 299-0111, Japan.
Many investigators reported the difficulty of predicting distant metastasis on the basis of histological findings [4, 9, 18, $25,35,36]$, although Chambers and Schwinn suggested a relationship between the metastasis and anaplastic histological features such as pleomorphism and hyperchromatism [5], which are known to be common in chordomas [5, 10, 26, 30]. Many studies suggested the proliferative potentials of neoplasms to be essential for evaluating their biological features [8, 14, 19-22, 24, 29], and thus, the proliferative potentials of chordomas should be elucidated with reference to the clinical course including tumor recurrence. Some reports on the clinical courses of intracranial chordomas have been published [11, 12, 31], however, the clinical and biological factors of intracranial chordomas regulating their future recurrence have not been determined. In order to elucidate the 
histopathological factors affecting the recurrence of intracranial chordomas, we studied the proliferative potential of intracranial chordomas immunohistochemically using antiKi-67 monoclonal antibody, MIB-1 [23]. In addition, we studied the expression of $\mathrm{p} 53$ protein of intracranial chordomas immunohistochemically [23]. In this paper, based on the results of our studies, we discussed the proliferative potentials of intracranial chordomas and referred to those of extracranial chordomas.

\section{Proliferative Potentials and Expression of p53 of Intracranial Chordomas with Consideration of Biological Tumor Progression: Our Experiences}

From March 1986 to November 1995, we treated surgically 17 tumors from 10 patients with intracranial chordoma. They were comprised of tumors from 5 male and 5 female patients with an average age of 39.9 years. Among these 17 tumors, there were 10 recurrent tumors $(58.8 \%)$. The clinical courses of all the patients had been followed for more than two and a half years. In patients with recurrent tumors, tumor specimens obtained during the initial surgery, if available, as well as those obtained during the surgery for recurrent tumors were analyzed.

The clinical profile of each patient, including age and sex of the patient and location and therapeutic modalities of the tumor, is summarized in Table 1. In this paper, the word 'recurrence' is used when the follow-up radiological examination revealed the development of a tumor which had been removed totally or subtotally during prior surgery. The word 'regrowth' is used when the enlargement of the tumor which had been removed partially during the prior surgery was shown on the follow-up radiological examination.

\section{Histopathological findings on hematoxylin-eosin staining}

Paraffin sections of surgically obtained materials were stained with hematoxylin-eosin. Neoplastic areas were delineated and served for histopathological diagnosis as chordomas. Of 17 tumors, 9 were typical physaliferous chordomas, 7 were physaliferous chordomas having chondroid components, and 1 tumor was a chondroid chordoma (Table 1). Nine typical physaliferous chordomas included 5 recurrent and 4 non-recurrent tumors. Seven physaliferous chordomas having chondroid components were comprised of 5 recurrent and 2 non-recurrent tumors. One chondroid chordoma did not show future recurrence (Table 1). There was no significant relationship between histopathological diagnosis and tumor recurrence. Nuclear atypia, pleomorphism and hyperchromatism were observed in both recurrent and non-recurrent tumors.

\section{MIB-1 and p53 immunohistochemical staining}

Recently, anti-Ki-67 monoclonal antibody, MIB-1, has become available for the retrospective analysis of tumor proliferative potentials using routinely processed paraffin sections [3]. Details of MIB-1 and p53 immunohistochemistry are described in our previous report [23]. Briefly, after deparaffinization, rehydration, and blockage of endogenous peroxidase activity with $0.3 \% \mathrm{H}_{2} \mathrm{O}_{2}$ in methanol, $4 \mu \mathrm{m}$ paraffin sections were dipped in $0.01 \mathrm{M}$ citrate $\mathrm{pH} 6.0$, and $\mathrm{Ki}$ 67 antigen was retrieved with microwave irradiation for 30 min (10 times for $3 \mathrm{~min}$ ). After pretreatment with normal goat sera, they were immunostained with commercially available anti-Ki-67 monoclonal antibody, MIB-1 (mouse, diluted 1:100 in bovine serum albumin (BSA)-phosphate buffered saline pH 7.4 (PBS)) (Immunotech S.A., Marseille, France), at room temperature for $1 \mathrm{hr}$. For the immunohistochemical staining of p53 protein, two anti-p53 monoclonal antibodies (DO-1 (mouse, not diluted, Immunotech S.A., Marseille, France) and PAb1801 (mouse, diluted 1:50 in BSA-PBS, Novocastra Laboratories, Newcastle, UK)) were used, and cells positively stained with both the antibodies were interpreted as p53 immunopositive cells. Biotinylated antibody against mouse immunoglobulin (IgG) (goat, Vectastain; Vector Laboratories Inc., Burlingame, Ca., USA) was applied as the secondary antibody for $30 \mathrm{~min}$. Immunoreactions were followed by streptavidin and biotin complex $(\mathrm{ABC})$ labeled with horseradish peroxidase using Vectastain's ABC kit (Vector Laboratories Inc., Burlingame, Ca., USA) for $30 \mathrm{~min}$, and developed with freshly prepared 3,3'-diaminobendizine tetrahydrochloride dissolved in $0.05 \mathrm{M}$ Tris- $\mathrm{HCl} \mathrm{pH} 7.6$ and $0.017 \% \mathrm{H}_{2} \mathrm{O}_{2}$ for 7 min. Nuclear staining was carried out with hematoxylin. For a positive control study of MIB-1 histochemistry, a brain metastatic tissue of colon cancer was used, and for positive control studies of p53 immunohistochemistry, a gastric cancer tissue, which had already been proven to be immunopositive for p53 protein, was used. For a negative control study, normal murine serum was substituted for the primary antibody.

Under high power magnification $(\times 400)$, the entire tissue sections were examined, and the number of cells positively stained with MIB-1 was counted in several representative fields containing more than 1,000 cells in total. The ratio of MIB-1 immunopositive cells/total cells was indicated as MIB-1 staining index (SI). In tumors of heterogeneous distribution of the MIB-1 immunopositive cells, the area containing the largest number of MIB-1 immunostained cells was regarded as the area representing the proliferative activity of the tumor. The mean MIB-1 SI and its standard deviation (SD) of each corresponding group were calculated and their correlation was analyzed with unpaired t-test (Student's t-test).

The extent of positivity of p53 protein, referring to an approximation of the number of positively immunostained cells, was graded on a four-point scale as follows: '-', negative or staining of less than $1 \%$ of the tumor cells; '+', staining of $1-10 \%$ of the tumor cells; ' ++ ', staining of $10-50 \%$ of the tumor cells; ' +++ ', staining of more than $50 \%$ of the tumor cells.

MIB-1 SI and age and sex distribution (Table 1)

The mean MIB-1 SI of 8 tumors from 5 male patients 
Table 1. Summary of the patients with intracranial chordoma

\begin{tabular}{|c|c|c|c|c|c|c|c|c|c|}
\hline No & Patient & Age & Sex & Location & Treatment & Rec & Histology & $\begin{array}{l}\text { MIB-1 SI } \\
(\%)\end{array}$ & $\begin{array}{l}\text { p53 Immunohisto- } \\
\text { chemistry }\end{array}$ \\
\hline 1 & A & 31 & M & Parasellar & $\begin{array}{l}\text { Subtotal Removal } \\
\text { \& RAD (60Gy) }\end{array}$ & 1 & Physaliferous & 15.4 & + \\
\hline 2 & & 35 & M & Parasellar & Subtotal Removal & 2 & Physaliferous & 16.2 & + \\
\hline 3 & B & 27 & M & Suprasellar & Subtotal Removal & 1 & Physaliferous & 8.50 & + \\
\hline 4 & & 28 & M & Suprasellar & $\begin{array}{l}\text { Subtotal Removal } \\
\& \text { RAD (70Gy) }\end{array}$ & 2 & Physaliferous & 6.26 & + \\
\hline 5 & & 30 & M & Parasellar & Total Removal & 3 & Physaliferous & 7.10 & ++ \\
\hline 6 & $\mathrm{C}$ & 50 & $\mathrm{~F}$ & Sphenoid Sinus & $\begin{array}{l}\text { Subtotal Removal } \\
\text { \& RAD (70Gy) }\end{array}$ & 1 & $\begin{array}{l}\text { Physaliferous with } \\
\text { Chondroid Component }\end{array}$ & 9.69 & + \\
\hline 7 & & 52 & $\mathrm{~F}$ & Suprasellar & Subtotal Removal & 2 & $\begin{array}{l}\text { Physaliferous with } \\
\text { Chondroid Component }\end{array}$ & 6.37 & - \\
\hline 8 & & 52 & $\mathrm{~F}$ & Suprasellar & Total Removal & 3 & $\begin{array}{l}\text { Physaliferous with } \\
\text { Chondroid Component }\end{array}$ & 12.4 & + \\
\hline 9 & & 53 & $\mathrm{~F}$ & Parasellar & Total Removal & 4 & $\begin{array}{l}\text { Physaliferous with } \\
\text { Chondroid Component }\end{array}$ & 12.4 & + \\
\hline 10 & & 54 & $\mathrm{~F}$ & Parasellar & Total Removal & 5 & $\begin{array}{l}\text { Physaliferous with } \\
\text { Chondroid Component }\end{array}$ & 8.00 & + \\
\hline 11 & $\mathrm{D}$ & 43 & $\mathrm{~F}$ & Parasellar & $\begin{array}{l}\text { Total Removal } \\
\text { No Radiotherapy }\end{array}$ & 0 & Chondroid & 2.00 & - \\
\hline 12 & $\mathrm{E}$ & 22 & $\mathrm{~F}$ & Parasellar & Total Removal & 0 & Physaliferous & 0.44 & - \\
\hline 13 & $\mathrm{~F}$ & 34 & M & Clivus & Subtotal Removal & 0 & Physaliferous & 0.00 & - \\
\hline 14 & G & 46 & $\mathrm{~F}$ & Clivus & $\begin{array}{l}\text { Subtotal Removal } \\
\& \text { RAD (60Gy) }\end{array}$ & 0 & $\begin{array}{l}\text { Physaliferous with } \\
\text { Chondroid Component }\end{array}$ & 1.96 & - \\
\hline 15 & $\mathrm{H}$ & 15 & M & Clivus & $\begin{array}{l}\text { Subtotal Removal } \\
\& \text { RAD (65Gy) }\end{array}$ & 0 & $\begin{array}{l}\text { Physaliferous with } \\
\text { Chondroid Component }\end{array}$ & 5.64 & - \\
\hline 16 & I & 43 & $\mathrm{~F}$ & Jugular Foramen & $\begin{array}{l}\text { RAD (70Gy) } \\
\& \text { Total Removal }\end{array}$ & 0 & Physaliferous & 5.00 & - \\
\hline 17 & $\mathrm{~J}$ & 55 & M & Parasellar & $\begin{array}{l}\text { Partial Removal } \\
\& \text { RAD (71Gy) }\end{array}$ & 0 & Physaliferous & 4.89 & - \\
\hline
\end{tabular}

Sex: $\mathrm{F}=$ female, $\mathrm{M}=$ male, $\mathrm{RAD}$ : radiotherapy

Rec: $0=$ non-recurrent tumor, $1=$ recurrent tumor, initial surgery, $2=$ recurrent tumor, second recurrence, $3=$ recurrent tumor, third recurrence, $4=$ recurrent tumor, fourth recurrence, $5=$ recurrent tumor, fifth recurrence

M: months, SD: standard deviation

p53: '-', negative or staining of less than $1 \%$ of the tumor cells; '+', staining of $1-10 \%$ of the tumor cells; '++', staining of $10-50 \%$ of the tumor cells; ' +++ ', staining of more than $50 \%$ of the tumor cells.

with chordomas was $8.0 \%$ (SD 5.4), whereas that of 9 tumors from 5 female patients was $6.5 \%$ (SD 4.5). There was no statistically significant difference in these two groups $(p>0.05)$. There was no significant correlation between patients' age and MIB-1 SI.

\section{MIB-1 SI and location of chordomas (Table 1)}

The present series comprised 8 parasellar, 4 suprasellar, 3 clival, 1 sphenoid sinus and 1 jugular foramen chordomas. Their mean MIB-1 staining indices were $8.3 \%, 8.4 \%, 2.5 \%$, $9.7 \%$ and $5 \%$, respectively. There was no apparent relationship between tumor location and MIB-1 SI.

Histopathological findings, recurrence, MIB-1 and p53 immunohistochemical staining (Fig. 1, Table 1)

The representative HE stainings, MIB-1 and p53 immunohistochemical stainings of the recurrent (Tumor 9) and non-recurrent (Tumor 14) tumors are presented in Fig. 1. Nuclear atypia, pleomorphism and hyperchromatism were observed both in a recurrent (Tumor 9, MIB-1 SI 12.4\%, p53 immunopositive) tumor and in a non-recurrent (Tumor 14, MIB-1 SI 1.96\%, p53 immunonegative) tumor. These histopathological findings, which generally suggest malignant characteristics of the tumor, were commonly noted in both recurrent and non-recurrent tumors, and were found to have no relationship with MIB-1 SI and p53 immunoreactivity.

\section{MIB-1 SI and recurrence (Fig. 2, Table 1)}

The mean MIB-1 SI of non-recurrent tumors was $2.8 \%$ (SD 2.3), whereas that of all the recurrent tumors was $10.2 \%$ (SD 3.7) (Fig. 2). There was a statistically significant difference in these two groups $(\mathrm{p}=0.0003)$. One of recurrent chordomas has a MIB-1 SI as high as $16.2 \%$ (Table 1). Confined to the initial tumors of recurrent chordomas, their mean MIB-1 SI was $11.2 \%$ (SD 2.1), which was statistically significantly higher than that of non-recurrent chordomas (2.8\% (SD 2.3)) $(\mathrm{p}=0.0021)($ Fig. 2). 

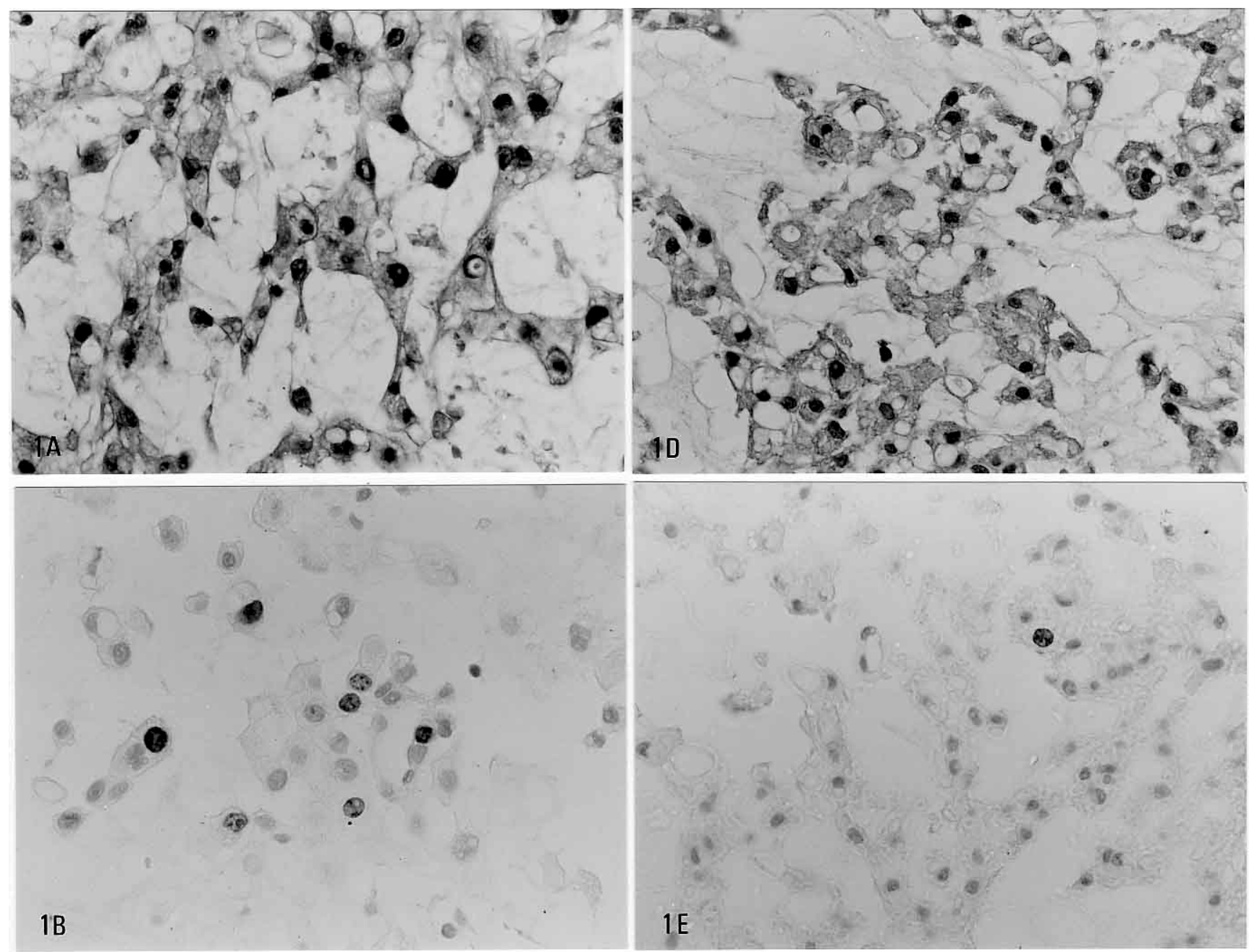

$1 \mathrm{~B}$
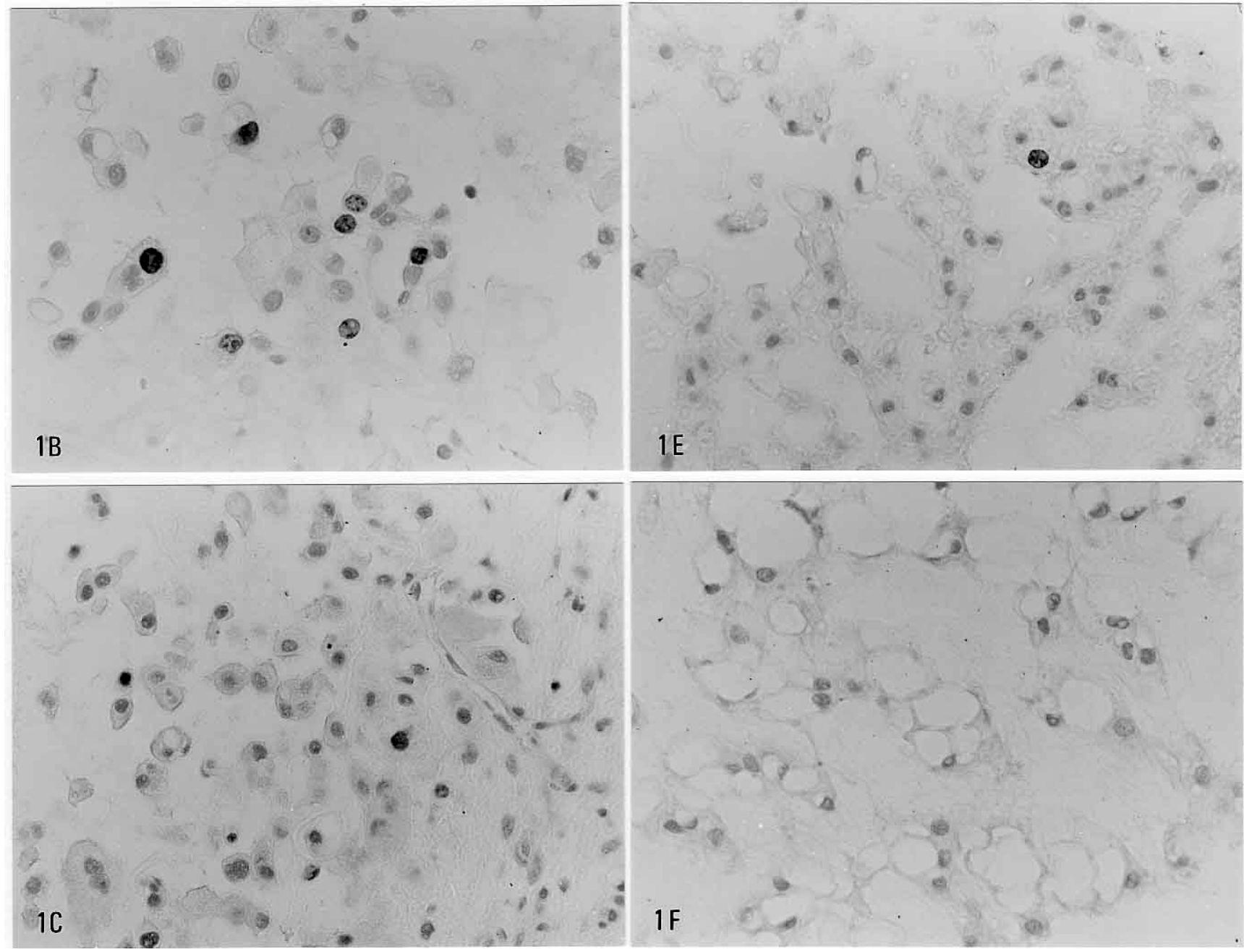

Fig. 1. The representative HE stainings, MIB-1 and p53 immunohistochemical stainings of the recurrent (Tumor 9, A: HE, B: MIB-1, C: p53) and non-recurrent (Tumor 14, D: HE, E: MIB-1, F: p53) tumors were presented $(\times 100)$. Nuclear atypia, pleomorphism and hyperchromatism were observed both in a recurrent (Tumor 9, MIB-1 SI 12.4\%, p53 immunopositive) tumor and in a non-recurrent (Tumor 14, MIB-1 SI 1.96\%, p53 immunonegative) tumor. These histopathological findings were commonly noted in both recurrent and non-recurrent tumors, and had no relationship with MIB-1 SI and p53 immunoreactivity. 


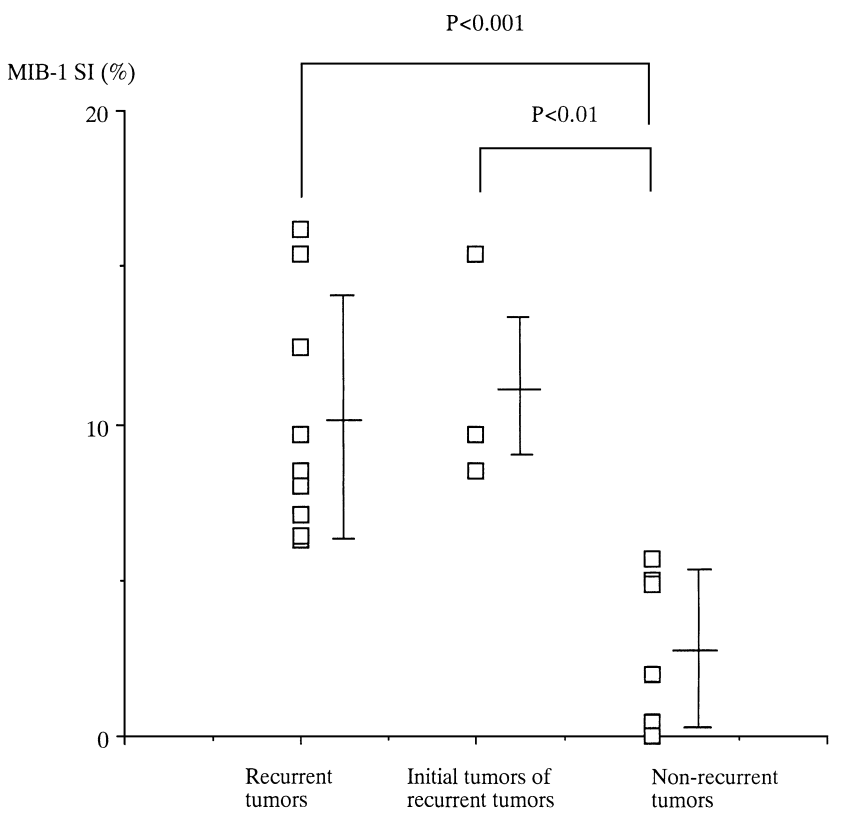

Fig. 2. Correlation with MIB-1 SI and recurrence of intracranial chordomas. The mean MIB-1 staining indices of non-recurrent and recurrent tumors were $2.8 \%$ (SD 2.3), and $10.2 \%$ (SD 3.7), respectively. There was a statistically significant difference in these two groups ( $\mathrm{p}=0.0003$ ). Confined to the initial tumors of recurrent chordomas, their mean MIB-1 SI was 11.2\% (SD 2.1), which was statistically significantly higher than that of non-recurrent chordomas $(\mathrm{p}=0.0021)$. Mean values \pm SDs were indicated on the figure.

The expression of 553 protein and its correlation with MIB-1 SI (Fig. 3, Table 1)

All the non-recurrent tumors showed p53 negative immunoreactivity, whereas 9 out of 10 recurrent tumors showed positive immunoreaction for p53 protein. p53 protein was immunostained in chordomas with MIB-1 SI higher than $6 \%$, except for a single tumor (Table 1). The mean MIB-1 staining indices of p53 immunonegative and immunopositive tumors were $3.1 \%$ (SD 2.6) and $10.7 \%$ (SD 3.6), respectively (Fig. 3). There was a statistically significant difference in these two groups $(\mathrm{p}=0.0003)$.

\section{Discussion on Proliferative Potentials of Intracranial Chordomas: Our Experiences}

The present studies on proliferative potentials of chordomas using MIB-1 SI have shown that there is a statistically significant correlation between MIB-1 SI and recurrence. There was no difference in the therapeutic modalities between the recurrent and the non-recurrent chordomas. Therefore, chordomas with high MIB-1 SI can be predicted to recur in the future, even though they are extirpated macroscopically during surgery. The major factor influencing the recurrence of a chordoma is supposed to be its proliferative potentials represented by MIB-1 SI. Karamitopoulou et al. studied MIB-1 SI in various central nervous system tumors [21]. Based on their assessment, recurrent chordomas have

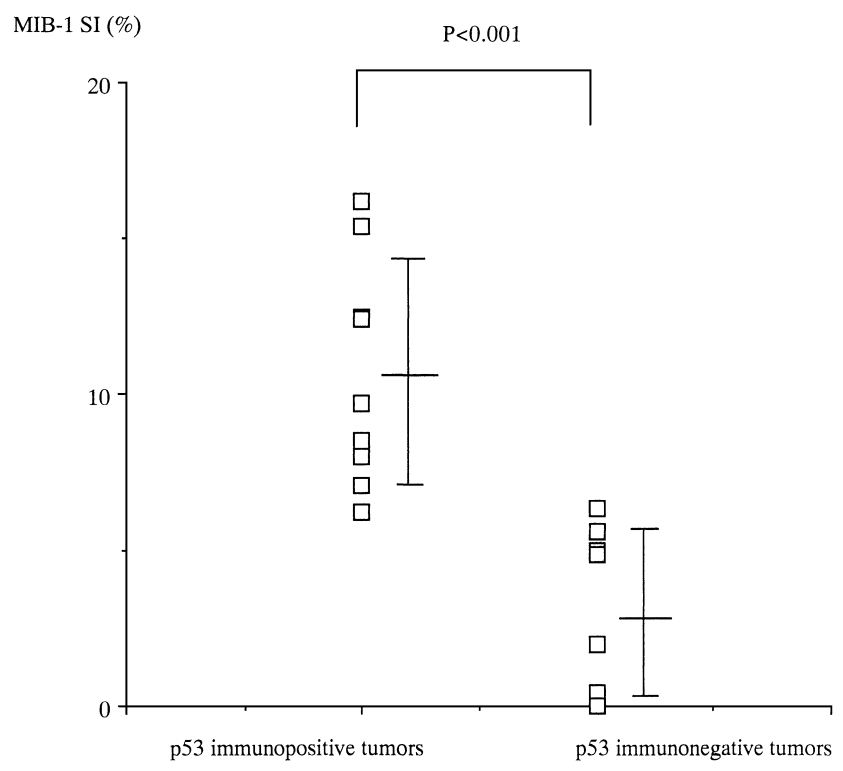

Fig. 3. Correlation with MIB-1 SI and p53 immunoreactivity. p53 was positively immunostained in chordomas with MIB-1 SI higher than $6 \%$, except for a single tumor. All the non-recurrent tumors showed p53 negative immunoreactivity, while 9 out of 10 recurrent tumors showed positive immunoreaction. The mean MIB-1 staining indices of p53 immunonegative and immunopositive tumors were $3.1 \%$ (SD 2.6) and 10.7\% (SD 3.6), respectively. There was a statistically significant difference in these two groups $(\mathrm{p}=0.0003$ ). Mean values \pm SDs were indicated on the figure.

higher MIB-1 SI than astrocytomas (2.03 \pm 2.03$)$, and some of them may have a MIB-1 SI equivalent to anaplastic astrocytomas (12.8 \pm 6.29$)$. Thus the proliferative potentials of some intracranial chordomas may possibly be identical to those of anaplastic astrocytomas.

As to histopathological findings of intracranial chordomas, many investigators reported the anaplastic histological features such as nuclear atypia, pleomorphism and hyperchromatism were common in chordomas [5, 10, 26, 30]. A previous report stated that the chondroid variant chordoma had a significantly more favorable outlook than the typical physaliferous chordoma [17]. In our series of 17 tumors, 9 were typical physaliferous chordomas (5 recurrent and 4 non-recurrent tumors), 7 were physaliferous chordomas having chondroid components ( 5 recurrent and 2 non-recurrent tumors), and 1 tumor was a chondroid chordoma that did not show future recurrence. There was no significant relationship between histopathological diagnosis and tumor recurrence. Nuclear atypia, pleomorphism and hyperchromatism were commonly noted in both recurrent and non-recurrent tumors, and were found to have no relationship with MIB-1 SI and p53 immunoreactivity. Therefore, from our studies, histopathological diagnosis and anaplastic histological features are considered not to be correlated with tumor recurrence of intracranial chordomas. The analyses on proliferative potentials using MIB-1 SI seem to be useful in 
predicting the future recurrence of intracranial chordoma. Examination of proliferative potentials of chordomas using MIB-1 SI is important for their biological and histopathological analyses and the prediction of future recurrence.

Anti-p53 antibodies used in this study can recognize both wild and aberrant types of p53 protein. Wild type p53 protein has been shown by recent investigations to be involved in negative regulation of cell proliferation; it induces p21 protein, which combines with the complex of cyclin and cyclin-dependent kinase (cdk) at the $\mathrm{G}_{1}$ phase and prevents a cell from entry into the $S$ phase [37], whereas aberrant $p 53$ protein has lost this negative regulation of cell growth. Wild type p53 protein, which has a very short half-life of only 20 min, has generally been considered to be undetectable with an immunohistochemical method using anti-p53 antibody. According to the recent reports, wild type p53 protein may be accumulated in the nucleoli due to the defective ubiquitin pathway [6]. Aberrant p53 protein, which forms stable complexes with heat shock protein (hsp) 70 and some other proteins, has a longer half-life of several hours and thus is visible with an immunohistochemical method [15, 38]. Therefore, although it cannot be determined whether the p53 immunopositive chordomas in the present study express aberrant p53 protein or may have accumulated wild type p53 protein, statistical analyses showed that $\mathrm{p} 53$ protein was immunostained in chordomas with high MIB-1 SI and in recurrent chordomas, and demonstrated the close relationship among p53 immunoreactivity, MIB-1 SI, and recurrence.

\section{Proliferative Potentials of Extracranial Chordomas}

Naka et al. analyzed proliferative potentials of 17 chordomas including 12 primary, 4 recurrent, and 1 metastatic lesions with anatomical distribution of 6 base of skull, 2 cervical spine, and 8 sacrum, and 1 thigh (metastasis from base of skull) [27]. Focusing on the histopathological morphology, they subclassified 17 specimens with chordoma into two groups (ie, trabecular type showing trabecular patterns and solid type mainly consisting of a diffuse proliferation of tumor cells), and assigned them to histological grading according to the degree of nuclear atypia on a scale of 1 to 3 . They also estimated the proliferative activities using DNA flow cytometric and immunohistochemical techniques, indicated as the proliferative index $(\% \mathrm{~S}+\mathrm{G} 2+\mathrm{M}$ phase) and the MIB-1 SI, together with the overexpression of p53 protein, which was determined immunohistochemically if the tissues contained more than $5 \%$ of tumor cells exhibiting a positive immunoreaction. They found some correlation partly between anaplastic histological features, including either diffuse proliferation or high grade nuclear atypia, and the proliferative index, the MIB-1 SI or p53 overexpression. They considered that the preceding anaplastic histological features, including either diffuse proliferation or high grade nuclear atypia, together with p53 overexpression, were thus closely related to the proliferative activities in chordomas.
Bergh P et al. analyzed the prognostic factors in chordoma of the 30 sacral and 9 mobile spine occurring in 22 women and 17 men (median age, 55 years), with the mean follow-up of 8.1 years, ranging from 0.1 to 23 years [1]. Seventeen patients $(44 \%)$ developed local recurrences and 11 patients $(28 \%)$ developed metastasis. Twenty-seven tumors had low MIB-1 SI $(<1 \%), 4$ tumors had a moderate degree of MIB-1 SI, and 7 tumors had a relatively high MIB-1 SI (>5\%). The single case of dedifferentiated chordoma had $40 \%$ MIB-1 SI. They concluded that the only two histologically assessed features found to be prognostically significant were microscopic tumor necrosis and MIB-1 SI $>5 \%$. The other features such as cellularity, pleomorphism, number of spindle cells, predominance of physaliferous or epitheliod tumor cells, mitotic rate and necrosis were found to have little correlation with the clinical course.

Saito et al. reported on a 50-year-old male with a recurrent dedifferentiated chordoma, i.e. chordoma with a sarcomatous component, in the sacrococcygeal region [32]. The recurrent tumor showed features of pleomorphic cell sarcoma, which was proven to be a dedifferentiated chordoma. In the pleomorphic sarcomatous area, many mitotic figures were seen, and the MIB-1 SI was greater than $40 \%$. Nishigaya et al. reported an intradural retroclival extraosseous chordoma, which showed no tumor regrowth 5 years after operation [28]. MIB-1 SI of this tumor was $1.89 \%$, and this MIB-1 SI was comparable to the mean MIB-1 SI of non-recurrent tumors in our studies $(2.8 \%)$.

Stefanou et al. evaluated p53/MDM-2 protein overexpression and MIB-1 SI in different subtypes of human sarcomas, and their correlation with proliferative activity and patient outcome [34]. They analyzed 40 human sarcomas comprising 6 malignant fibrous histiocytomas, 1 fibrosarcoma, 1 dermatofibrosarcoma protuberans, 5 liposarcomas, 9 leiomyosarcomas, 1 rhabdomyosarcoma, 3 synovial sarcomas, 2 osteosarcomas, 1 chondrosarcoma, 4 Ewing's sarcomas, 2 Kaposi's sarcomas, 1 malignant haemangiopericytoma, 1 phylloides cystosarcoma, 1 neuroblastoma, 1 chordoma and 1 unclassified sarcoma. They found that p53 overexpression was associated with high tumor grade $(\mathrm{p}<0.05)$ and MIB-1 SI was correlated with reduced survival $(\mathrm{p}<0.05)$, but $\mathrm{p} 53$ overexpression was not significantly associated with either MIB-1 SI or with overall survival of the patients.

From these studies, the proliferative potentials of extracranial chordomas represented by MIB-1 SI and p53 overexpression are suggested to be closely related to their clinical courses, including recurrence and metastasis. Some investigators reported that histological findings such as sarcomatous changes, microscopic necrosis, diffuse proliferation and high grade nuclear atypia also have a relationship with the proliferative activities of chordomas.

\section{Conclusion}

In conclusion, recurrence of intracranial and extracranial chordoma are closely related to the proliferative potentials 
represented by MIB-1 SI and p53 overexpression. Both the examination on proliferative potentials of chordomas using MIB-1 SI and the study on the immunoreactivity of $\mathrm{p} 53$ protein are important for their biological and histopathological analyses and the prediction of future recurrence.

\section{References}

1. Bergh, P., Kindblom, L. G., Gunterberg, B., Remotti, F., Ryd, W. and Meis-Kindblom, J. M.: Prognostic factors in chordoma of the sacrum and mobile spine: a study of 39 patients. Cancer 88; 2122-2134, 2000.

2. Bouropoulou, V., Bosse, A., Roessner, A., Vollmer, E., Edel, G., Wuisman, P. and Härle, A.: Immunohistochemical investigation of chordomas: Histogenesis and differential diagnostic aspects. Curr. Top. Pathol. 80; 182-203, 1989.

3. Cattoretti, G., Becker, M. H. G., Key, G., Duchrow, M., Schlüter, C., Galle, J. and Gerdes, J.: Monoclonal antibodies against recombinant parts of the Ki-67 antigen (MIB1 and MIB3) detect proliferating cells in microwave-processed formalin-fixed paraffin sections. J. Pathol. 168; 357-363, 1992.

4. Chalmers, J. and Heard, B. E.: A metastasing chordoma: a further note. J. Bone Joint Surg. Br. 54; 526-529, 1972.

5. Chambers, P. W. and Schwinn, C. P.: Chordoma. A clinicopathologic study of metastasis. Am. J. Clin. Pathol. 72; 765-776, 1979.

6. Chowdary, D. R., Dermody, J. J., Jha, K. K. and Ozer, H. L.: Accumulation of p53 in a mutant cell line defective in the ubiquitin pathway. Mol. Cell. Biol. 14; 1997-2003, 1994.

7. Dahlin, D. C. and MacCarty, C. S.: Chordoma: A study of fiftynine cases. Cancer 5; 1170-1178, 1952.

8. Egawa, M., Chano, T., Matsumoto, K., Okabe, H., Ishizawa, M. and Hukuda, S.: Kinetic analysis of malignant fibrous histiocytoma cells treated with anticancer agents in vivo. Acta Histochem. Cytochem. 32; 437-448, 1999.

9. Eisemann, M. L.: Sphenooccipital chordoma presenting as a nasopharyngeal mass. A case report. Ann. Otol. Rhinol. Laryngol. 89; 271-275, 1980.

10. Eriksson, B., Gunterberg, B. and Kindblom, L. G.: Chordoma. A clinicopathologic and prognostic study of a Swedish national series. Acta Orthop. Scand. 52; 49-58, 1981.

11. Forsyth, P. A., Cascino, T. L., Shaw, E. G., Scheithauer, B. W., O'Fallon, J. R., Dozier, J. C. and Piepgras, D. G.: Intracranial chordomas: A clinicopathological and prognostic study of 51 cases. J. Neurosurg. 78; 741-747, 1993.

12. Gay, E., Sehkar, L. N., Rubinstein, E., Wright, D. C., Sen, C., Janecka, I. P. and Snyderman, C. H.: Chordomas and chondrosarcomas of the cranial base: Results and follow-up of 60 patients. Neurosurgery 36; 887-897, 1995.

13. Gentil, F. and Coley, B. L.: Sacrococcygeal chordoma. Ann. Surg. 127; 432-455, 1948

14. Gerdes, J., Lemke, H., Baisch, H., Wacker, H. H., Schwab, U. and Stein, H.: Cell cycle analysis of a cell proliferation-associated human nuclear antigen defined by the monoclonal antibody $\mathrm{Ki}-$ 67. J. Immunol. 133; 1710-1715, 1984.

15. Gronostajski, R. M., Goldberg, A. J. and Pardee, A. B.: Energy requirement for degradation of tumor-associated protein p53. Mol. Cell. Biol. 4; 442-448, 1984.

16. Heaton, J. M. and Turner, D. R.: Reflections on notochordal differentiation arising from a study of chordomas. Histopathology 9 ; 543-550, 1985.

17. Heffelfinger, M. J., Dahlin, D. C., Maccarty, C. S. and Beabout, J. W.: Chordomas and cartilaginous tumors at the skull base. Cancer 32; 410-420, 1973.

18. Higinbotham, N. L., Phillips, R. F., Farr, H. W. and Hustu, H. O.: Chordoma. Thirty-five-year study at Memorial Hospital. Cancer
$20 ; 1841-1850,1967$.

19. Hoshino, T., Nagashima, T., Murovic, J. A., Wilson, C. B. and Davis, R. L.: Proliferative potential of human meningiomas of brain. Cancer 58; 1466-1472, 1986.

20. Karamitopoulou, E., Perentes, E., Melachrinou, M. and Maraziotis, T.: Proliferating cell nuclear antigen immunoreactivity in human central nervous system neoplasms. Acta Neuropathol. 85; 316-322, 1993

21. Karamitopoulou, E., Perentes, E., Diamantis, I. and Maraziotis, T.: Ki-67 immunoreactivity in human central nervous system neoplasms: a study with MIB 1 monoclonal antibody on archival material. Acta Neuropathol. 87; 47-54, 1994.

22. Kim, Y. S., Lee, S. J., Kim, I., Kim, G. M. and Paik, S. R.: The use of alkaline EDTA solution improves heat-induced epitope retrieval for immunohistochemical localization of MIB-1 antigen. Acta Histochem. Cytochem. 32; 287-294, 1999.

23. Matsuno, A., Sasaki, T., Nagashima, T., Matsuura, R., Tanaka, H., Hirakawa, M., Murakami, M. and Kirino, T.: Immunohistochemical examination on proliferative potentials and the expression of cell cycle related proteins of intracranial chordomas. Hum. Pathol. 28; 714-719, 1997.

24. Matsuno, A., Fujimaki, T., Sasaki, T., Nagashima, T., Ide, T., Asai, A., Matsuura, R., Utsunomiya, H. and Kirino, T.: Clinical and histopathological analysis on proliferative potentials of recurrent and non-recurrent meningiomas. Acta Neuropathol. 91; 504-510, 1996.

25. Meis, J. M., Raymond, A. K., Evans, H. L., Charles, R. E. and Giraldo, A. A.: "Dedifferentiated" chordoma. A clinicopathologic and immunohistochemical study of three cases. Am. J. Surg. Pathol. 11; 516-525, 1987.

26. Murad, T. M. and Murthy, M. S.: Ultrastructure of a chordoma. Cancer 25; 1204-1215, 1970.

27. Naka, T., Fukuda, T., Chuman, H., Iwamoto, Y., Sugioka, Y., Fukui, M. and Tsuneyoshi, M.: Proliferative activities in conventional chordoma: a clinicopathologic, DNA flow cytometric, and immunohistochemical analysis of 17 specimens with special reference to anaplastic chordoma showing a diffuse proliferation and nuclear atypia. Hum. Pathol. 27; 381-388, 1996.

28. Nishigaya, K., Kaneko, M., Ohashi, Y. and Nukui, H.: Intradural retroclival chordoma without bone involvement: no tumor regrowth 5 years after operation. Case report. J. Neurosurg. 88; 764-768, 1998

29. Nishikawa, T., Arai, S., Uobe, K., Wato, M., Tominaga, K., Masuno, K., Mori, M., Yoshida, S., Kobayashi, H. and Tanaka, A.: A double staining method for histone $\mathrm{H} 3$ mRNA and p53 protein in oral tumors using in situ hybridization and immunohistochemistry. Acta Histochem. Cytochem. 32; 327-332, 1999.

30. O’Connell, J. X., Renard, L. G., Liebsch, N. J., Efird, J. T., Munzenrider, J. E. and Rosenberg, A. E.: Base of skull chordoma. A correlative study of histologic and clinical features of 62 cases. Cancer 74; 2261-2267, 1994.

31. Rich, T. A., Schiller, A., Suit, H. D. and Mankin, H. J.: Clinical and pathologic review of 48 cases of chordomas. Cancer 56; 182-187, 1985.

32. Saito, A., Hasegawa, T., Shimoda, T., Toda, G., Hirohashi, S., Tajima, G. and Moriya, Y.: Dedifferentiated chordoma: a case report. Jpn. J. Clin. Oncol. 28; 766-771, 1998.

33. Smith, J., Ludwig, R. L. and Marcove, R. C.: Sacrococcygeal chordoma. A clinicoradiological study of 60 patients. Skeletal. Radiol. 16; 37-44, 1987.

34. Stefanou, D. G., Nonni, A. V., Agnantis, N. J., Athanassiadou, S. E., Briassoulis, E. and Pavlidis, N.: p53/MDM-2 immunohistochemical expression correlated with proliferative activity in different subtypes of human sarcomas: a ten-year follow-up study. Anticancer Res. 18; 4673-4681, 1998.

35. Volpe, R. and Mazabraud, A.: A clinicopathologic review of 25 cases of chordoma (a pleomorphic and metastasizing neoplasm). 
Am. J. Surg. Pathol. 7; 161-170, 1983.

36. Wu, K. K., Mitchell, D. C. and Guise, E. R.: Chordoma of the atlas. J. Bone Joint Surg. Am. 61; 140-141, 1979.

37. Xiong, Y., Hannon, G. J., Zhang, H., Casso, D., Kobayashi, R. and Beach, D.: p21 is a universal inhibitor of cyclin kinases.
Nature 366; 701-704, 1993.

38. Zambetti, G. P. and Levine, A. J.: A Comparison of the biological activities of wild-type and mutant p53. FASEB. J. 7; 855-865, 1993. 